\title{
Pilot Evaluation of Dermal Contamination by Antineoplastic Drugs among Hospital Pharmacy Personnel
}

\author{
Chun-Yip Hon, George Astrakianakis, Quinn Danyluk, and Winnie Chu
}

\begin{abstract}
Background: It is believed that health care workers are exposed to antineoplastic drugs primarily via dermal contact. However, levels of occupational dermal contamination in Canada have not been formally investigated.
\end{abstract}

Objective: To determine the potential dermal exposure to antineoplastic drugs among hospital pharmacy personnel in a metropolitan area in British Columbia.

Methods: Six hospital pharmacies in the Vancouver area participated in this pilot study. Three pharmacy workers (a technician responsible for preparing drugs, a pharmacist responsible for checking drugs before administration, and a technician not responsible for preparing drugs but working in the pharmacy department) were selected from each site, for a total of 18 participants. Each worker's hands were wiped with a premoistened tissue (one wipe per person), and the wipes were subsequently analyzed by high-performance liquid chromatography tandem mass spectrometry to determine levels of both cyclophosphamide and methotrexate (total of 36 analyses).

Results: At 3 of the 6 sites, at least one hand-wipe sample was above the analytical detection limit. Of the 18 analyses from the 3 "positive" sites, $5(28 \%)$ had measurable levels of cyclophosphamide and methotrexate. Cyclophosphamide was detected in 3 samples (geometric mean $0.98 \mathrm{ng}$, geometric standard deviation $2.72 \mathrm{ng}$, range from below limit of detection to $3.96 \mathrm{ng}$ ) and methotrexate in 2 samples (geometric mean $0.27 \mathrm{ng}$, geometric standard deviation $2.57 \mathrm{ng}$, range from below limit of detection to $0.27 \mathrm{ng}$ ).

Conclusions: The results of this pilot study suggest that hospital pharmacy workers in Metro Vancouver are probably exposed to antineoplastic drugs, given that detectable levels of drug were found on the hands of some personnel. Further studies are recommended to confirm these findings.

Key words: antineoplastic drugs, occupational exposure, dermal contamination, risk assessment, pilot study

Can J Hosp Pharm 2011;64(5):327-332

\section{RÉSUMÉ}

Contexte : D'aucuns croient que les travailleurs de la santé sont exposés aux agents anticancéreux principalement par voie cutanée. Cependant, les taux de contamination professionnelle par voie cutanée au Canada n'ont pas fait l'objet d'études officielles.

Objectif : Déterminer l'exposition cutanée potentielle aux agents anticancéreux du personnel des pharmacies d'hôpitaux dans une région métropolitaine de Colombie-Britannique.

Méthodes : Six pharmacies d'hôpitaux de la région de Vancouver ont participé à cette étude pilote. Trois membres du personnel de la pharmacie (un technicien responsable de la préparation des médicaments; un pharmacien responsable de la vérification des médicaments avant leur administration; et un technicien non responsable de la préparation des médicaments, mais travaillant dans le service de pharmacie) ont été choisis dans chaque centre, pour un total de 18 sujets. Les mains de chaque sujet ont été essuyées au moyen d'une lingette (une par sujet), puis les lingettes ont été analysées par chromatographie liquide haute performance couplée à la spectrométrie de masse en tandem afin de déterminer les concentrations de cyclophosphamide et de méthotrexate, pour un total de 36 analyses.

Résultats : Dans trois centres, au moins un échantillon de lingette présentait une concentration supérieure à la limite de détection analytique. Des 18 analyses provenant de ces trois centres, cinq (28\%) ont révélé des concentrations mesurables de cyclophosphamide ou de méthotrexate. On a détecté de la cyclophosphamide dans trois échantillons (moyenne géométrique de $0,98 \mathrm{ng}$, écart-type géométrique de 2,72, plage allant d'une valeur sous la limite de détection à $3,96 \mathrm{ng}$ ) et du méthotrexate dans deux échantillons (moyenne géométrique de 0,27 ng, écart-type géométrique de 2,57 , plage allant d'une valeur sous la limite de détection à $0,27 \mathrm{ng})$.

Conclusions : Les résultats de cette étude pilote suggèrent que les membres du personnel des pharmacies d'hôpitaux de Metro Vancouver sont probablement exposés à des agents anticancéreux, étant donné les concentrations détectables de médicaments trouvées sur les mains de certains employés. D'autres études sont recommandées afin de confirmer ces résultats.

Mots clés : agents anticancéreux, contamination professionnelle, contamination par voie cutanée, évaluation du risque, étude pilote

[Traduction par l'éditeur] 


\section{INTRODUCTION}

A ntineoplastic drugs are routinely used to treat patients with various types of cancer. These drugs act by interfering with the ability of the cancer cells to proliferate. However, because of their nonselective nature, antineoplastic agents can also affect normal cells. ${ }^{1}$ As such, health care workers who handle antineoplastic agents, including stocking vials, transporting solutions, or preparing them for administration, are at risk for exposure, which may result in a variety of adverse health effects, including liver toxicity, reproductive effects, and cancer. ${ }^{2}$

Despite the use of exposure-control measures during handling and preparation of antineoplastics, various studies have reported drug contamination of numerous surfaces within health care facilities, including biological safety cabinets, countertops, and floors in the pharmacy department. ${ }^{3-7}$ It has been suggested that contamination of these surfaces may result from poor handling practices and/or inadequate cleaning. ${ }^{8}$ The widespread contamination of work surfaces in a hospital increases the risk for skin contact with these drugs. This problem is notable because, although there are other routes of exposure, studies have indicated that dermal absorption is the main route of occupational exposure to antineoplastic drugs. ${ }^{9.12}$

To the authors' knowledge, few studies have examined dermal contamination among hospital workers. In a study performed in the Netherlands, Fransman and others ${ }^{13}$ found contamination on the hands of pharmacy technicians involved with drug preparation. In a more recent study, the same authors examined specific tasks associated with potential exposure to antineoplastic drugs. ${ }^{9}$ They found that all gloves used during preparation of drugs became contaminated, but they observed only one instance of contamination of a worker's hands inside the gloves. To the authors' knowledge, no similar study involving Canadian health care workers has been conducted. A pilot study was therefore undertaken to assess the dermal contamination of select personnel in hospital pharmacies in the metropolitan Vancouver region of British Columbia. Handwipe samples were simultaneously analyzed for both cyclophosphamide and methotrexate, 2 common antineoplastic drugs that are handled and prepared at the participating facilities and that have been used as markers in previous studies of occupational exposure. ${ }^{6,9}$

\section{METHODS}

\section{Hand-Wipe Samples}

Six hospital pharmacies within Metro Vancouver participated in the study. Institutional ethics approval was obtained from each institution before any samples were collected. At each of the 6 facilities, 3 pharmacy workers were asked to participate, one of whom was responsible for preparing antineoplastic drugs (i.e., a pharmacy technician responsible for drug preparation) and 2 who of whom were not involved in drug preparation but who worked in the pharmacy department (a pharmacist and a pharmacy technician not involved with drug preparation). A total of 18 hand wipes were collected, and each wipe was analyzed for the 2 drugs of interest (total of 36 analyses), as described below.

All samples were collected in June and July 2006 by the same member of the research team (a research assistant). Potential participants were selected for the study on the basis of convenience sampling. Following a discussion with each site's pharmacy manager, recruitment of potential participants was dependent on individuals job titles and assigned duties on the day of the site visit. If an individual was working in 1 of the 3 specified job categories on the day of the site visit, the individual was approached by the research team member and asked if he or she would be willing to participate. Each worker was given a written overview of the study and was asked to provide written consent before collection of samples.

Participants who were wearing gloves were asked to remove them before sampling. For pharmacy technicians who were preparing drugs, the sampling was performed immediately after they emerged from the drug preparation area but before they washed their hands, to allow assessment of any drug permeation through the gloves. For all other participants, sampling was performed at their convenience during the course of their duties, and they might or might not have washed their hands before sampling.

The sample collection method was a modified version of the protocol developed by Sabatini and others. ${ }^{14}$ Briefly, this method involved wiping the front and back of both hands of each worker with a Kimwipe tissue (Kimberly-Clark, Dallas, Texas) that had been premoistened with $0.75 \mathrm{~mL}$ of $0.1 \mathrm{~mol} / \mathrm{L}$ ammonium acetate solution. The wipe was then placed in a $20-\mathrm{mL}$ vial, which was subsequently labelled and placed in a portable cooler with ice packs. The researcher collecting the samples wore a fresh pair of gloves to collect the hand-wipe sample for each participant.

\section{Sample Analyses}

All samples were transported on ice on the day of sampling to the laboratory of the School of Environmental Health at the University of British Columbia, Vancouver. The samples were transferred from the portable cooler into a freezer and were stored at $-20^{\circ} \mathrm{C}$ until the time of analysis. Each sample was simultaneously analyzed for the presence of cyclophosphamide and methotrexate, by means of an analytical method developed by Sabatini and others ${ }^{14}$ and modified by $\mathrm{Chu}$ and Barnjak. ${ }^{15}$ The chemical analysis was done using highperformance liquid chromatography tandem mass spectrometry (HPLC-MS/MS) with the electrospray ionization in the 
positive-ion mode. The system components were a Waters Acquity Ultra-Performance Liquid Chromatography (UPLC) liquid chromatograph, a Waters Micromass Quattro Premier $\mathrm{XE}$ tandem mass spectrometer, and an Acquity UPLC BEH (ethylene bridged hybrid) $\mathrm{C}_{18} 1.7 \mu \mathrm{m}, 2.1 \times 100 \mathrm{~mm}$ column (Waters Corporation, Milford, Massachusetts). The mass spectrometer was operated in the multiple-reaction monitoring mode. The HPLC mobile phase was $0.2 \%$ formic acid in a $1: 1$ mixture of methanol and deionized water.

The samples were analyzed in 3 separate batches, because of limited availability of the analytical instrument (which was located in another university department). Batch 1 consisted of samples collected from sites A to D (i.e., 4 sites), batch 2 consisted of samples from site E, and batch 3 consisted of samples from site F. Different limits of detection were obtained for each of the 3 analytical batches, and contamination levels for each sample were reported in nanograms per wipe (ng/wipe). In all analytical batches, the limit of detection was determined on the basis of the average value for a laboratory blank plus 3 standard deviations, commonly known as the "blank determination" method. ${ }^{16}$ All nondetectable values were transformed to half of the respective limit of detection. ${ }^{17}$ Then, because occupational exposure data are often log-normally distributed, the results were log-transformed, and the resulting geometric mean and geometric standard deviation were calculated for each of the 2 drugs of interest.

All statistical analyses were performed with SPlus version 8.0 for Windows (Insightful Corporation, Seattle, Washington).

\section{RESULTS}

\section{Work Environment and Participants}

All participating facilities were acute care hospitals. The guidelines implemented for safe handling of antineoplastic drugs varied slightly from one site to another; closed systems were not used at any of the sites. At all sites, a chemotherapycertified pharmacy technician prepared antineoplastic drugs in a class II, type B biological safety cabinet. With the exception of site $\mathrm{B}$, all of the cabinets were situated in an isolation room designated solely for preparation of antineoplastic drugs. This isolation room was adjacent to the dispensary, where nonantineoplastic drugs were handled. At site B, antineoplastic drugs were prepared in the same area where non-antineoplastic drugs were handled. Each participating pharmacy technician tasked with drug preparation wore, at a minimum, a gown, gloves, and a surgical mask while preparing antineoplastic drugs in the biological safety cabinet.

Study participants who were not involved with preparing antineoplastic drugs were either pharmacists or pharmacy technicians. The pharmacists were responsible for checking the final prepared products. The pharmacy technicians not involved with drug preparation performed other duties in the pharmacy department, such as administrative work or setting up instruments and supplies for preparation of other medications. All pharmacists, with the exception of those at site $\mathrm{F}$, verified the drug preparations outside of the isolation room. The protocol for checking drugs at site $\mathrm{F}$ required the pharmacist to go into the isolation room to confirm the drug formulations. None of the pharmacy technicians who performed their tasks in the dispensary were observed entering the isolation room by the research team member. The use of gloves by the pharmacists and the pharmacy technicians not involved with drug preparation varied at the individual level: some wore gloves, but others did not. No individual from either job category was observed to wear double sets of gloves.

\section{Dermal Contamination Levels}

Of the 6 participating sites, only 3 (sites $\mathrm{B}, \mathrm{C}$, and $\mathrm{E}$ ) had detectable levels of at least one of the antineoplastic drugs (Table 1). Five (28\%) of the 18 hand wipes from these 3 sites had measurable levels of drug contamination (i.e., above the limit of detection). None of the hand wipes had detectable levels of both drugs. Cyclophosphamide was detected in 3 samples (geometric mean $0.98 \mathrm{ng}$, geometric standard deviation $2.72 \mathrm{ng}$, range from below limit of detection to $3.96 \mathrm{ng}$ ). Methotrexate was found in 2 samples (geometric mean $0.27 \mathrm{ng}$, geometric standard deviation $2.57 \mathrm{ng}$, range from below limit of detection to $0.27 \mathrm{ng}$ ). At site B, 2 participants, both of whom were pharmacy technicians, had detectable levels of cyclophosphamide. Site C also had a pharmacy technician with a detectable level of cyclophosphamide. The 2 samples with detectable levels of methotrexate were from site E: one from a pharmacy technician preparing the drugs and the other from the pharmacist checking the drugs.

\section{DISCUSSION}

The results of this pilot study confirmed that workers in certain hospital pharmacies in Metro Vancouver are at risk of dermal exposure to antineoplastic drugs. At 3 of the 6 participating sites (sites B, C, and E), at least one person had a measurable level of cyclophosphamide or methotrexate. Of the total of 18 analyses for wipes obtained at sites B, C, and E (i.e., 9 wipes analyzed for the 2 drugs of interest), 5 (28\%) had levels of antineoplastic drugs greater than the limit of detection. To the authors' knowledge, there is no established dose-response relation for antineoplastic drugs; as such, we cannot comment on the health implications of these values. However, cyclophosphamide is classified as a confirmed human carcinogen, according to the International Agency for Research on Cancer. ${ }^{18}$ More generally, antineoplastic drugs have been associated with reproductive toxic effects among occupational- 


\section{Table 1. Methotrexate and Cyclophosphamide Contamination on Hands of Pharmacy Personnel*}

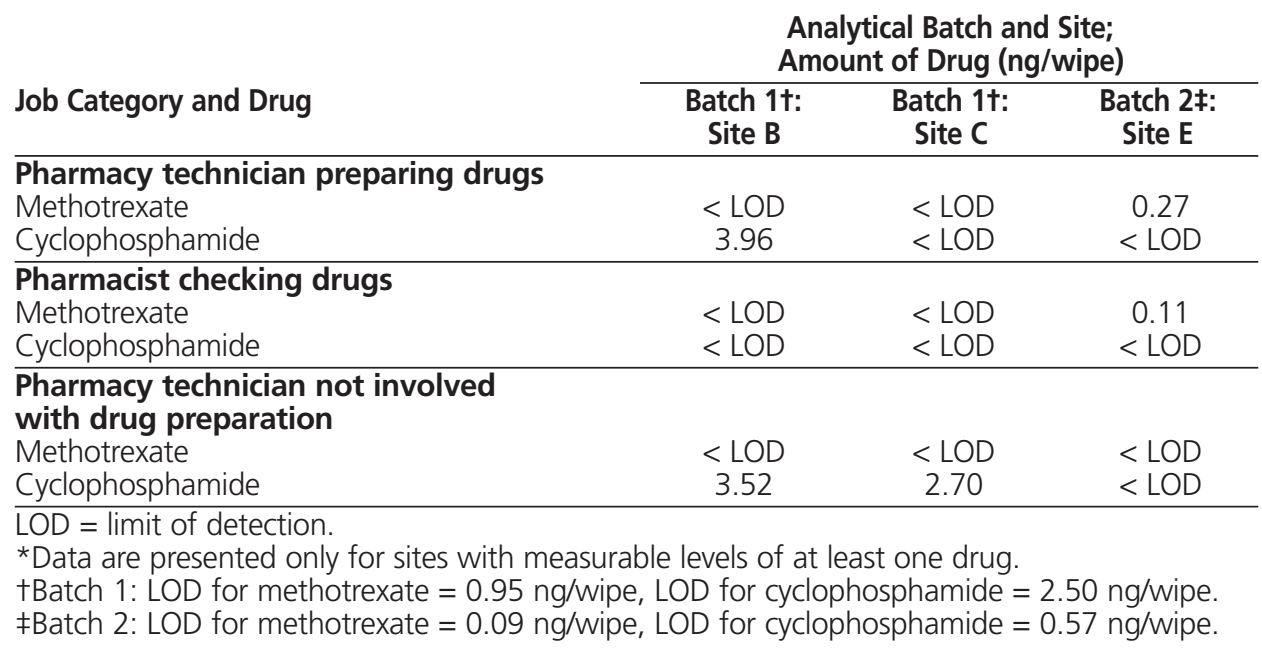

ly exposed pharmacy personnel and oncology nurses. ${ }^{19}$ Previous studies have demonstrated evidence of the mutagenicity of antineoplastic drugs through various biomarkers. ${ }^{20-22}$ In a study correlating occupational exposure to adverse health outcomes, Fransman and others ${ }^{23}$ found a positive $\log$-linear relation between dermal exposure to antineoplastic drugs and risk of premature delivery and low birth weight in a cohort of oncology nurses. In a recent study, McDiarmid and others ${ }^{24}$ found genetic abnormalities among oncology personnel who were handling anticancer drugs. In both of these studies, ${ }^{23,24}$ the antineoplastic drugs were mixed in a biological safety cabinet, and staff were required to wear gloves while handling drugs. As these work practices are the same as those employed by the sites participating in the current study, it is conceivable that pharmacy personnel in the current study were also at risk of the aforementioned adverse health outcomes.

Previous authors have reported that antineoplastic drugs can permeate through gloves, ${ }^{25}$ which may explain why pharmacy technicians involved with drug preparation in the current study had measurable drug contamination, even though they wore gloves when preparing the drugs. The reason why some workers who did not directly handle antineoplastic drugs (i.e., pharmacists and pharmacy technicians working in the dispensary) had dermal drug contamination is unclear. These workers may have been indirectly exposed to antineoplastic drugs through contact with the external surfaces of the commercially available drug vials. ${ }^{26}$ Such contamination might then have been distributed to other surfaces or objects, such as the prepared infusion bags. Another possibility is that the workers who prepared the drugs had contamination on the outside of their gloves, which might have been transferred to other objects that were shared and used throughout the pharmacy department, such as transport trays. ${ }^{27}$ These results support the need to investigate this exposure risk in a more rigorous fashion.
Comparison of the current findings with those of the 2 other occupational dermal contamination studies ${ }^{9,13}$ is difficult because of differences in the reported units of measure. In one of these studies, Fransman and others ${ }^{13}$ found that pharmacy technicians' hands had cyclophosphamide concentration rates of $0.002 \mathrm{ng} / \mathrm{cm}^{2}$ per minute while preparing drugs over a span of $100 \mathrm{~min}$. However, the duration of procedures was not documented in the current study. In a separate study, Fransman and others ${ }^{9}$ reported an average contamination of $13.6 \mathrm{ng}$ per task on the hands of pharmacy technicians (range $12.5-40.0 \mathrm{ng}$ per task). In the current study, wipe samples were not collected following completion of any particular task.

Given that the study reported here was a pilot study to assess the potential of antineoplastic drug contamination on the hands of pharmacy personnel in British Columbia, a number of limitations should be addressed. We are unable to explain why the dermal contamination levels varied among the 6 sites. Our goal was to ascertain if dermal exposure was possible; exploring the determinants of exposure is the topic of another study, now in progress. Individual factors that can affect dermal contamination levels, such as hand-washing practices, were also not evaluated. Again, the main goal of the study was to examine the likelihood of residual drug contamination on hands, not to evaluate the effectiveness of hand-washing practices. Another shortcoming was the small number of samples and the lack of replicates from any participants. Because this was a pilot study, we were constrained by limits on both time and financial resources. However, the fact that we did find dermal contamination suggests the need to explore this issue further. Finally, because the analytical instrument was situated in another department within the university, access to the instrument by our research team was limited to analyzing the samples in 3 separate batches, which resulted in 3 different 
limits of detection for each drug. If all of the samples had been run as a single batch, it is likely that more of the samples would have shown levels of contamination above detectable limits.

\section{CONCLUSIONS}

The results of this study suggest that workers in hospital pharmacies in one metropolitan area of British Columbia, including those not directly responsible for preparation of antineoplastic drugs, are at risk of dermal exposure to antineoplastic drugs. To the authors' knowledge, this is the first study of its kind in Canada to quantify dermal contamination levels of pharmacy workers exposed to this group of drugs. These findings are noteworthy, given the various control measures that current legislation and best practice guidelines specify are necessary to minimize occupational exposure. However, we caution that this was a pilot study and that additional research is necessary to assess the risk of dermal exposure to antineoplastic drugs among health care workers. Nevertheless, these results may serve as a warning that current control measures may be inadequate to eliminate contamination with antineoplastic drugs.

\section{References}

1. Connor TH. Hazardous anticancer drugs in health care: environmental exposure assessment. Ann NY Acad Sci 2006;1076:615-623.

2. NIOSH alert: Preventing occupational exposure to antineoplastic and other hazardous drugs in health care settings. NIOSH Publ No. 2004-165. Atlanta (GA): US Department of Health and Human Services, Public Occupational Safety and Health, Centers for Disease Control and Prevention, National Institute for Occupational Safety and Health; 2004.

3. Connor TH, Anderson RW, Sessink PJ, Broadfield L, Power LA. Surface contamination with antineoplastic agents in six cancer treatment centers in Canada and the United States. Am J Health Syst Pharm 1999;56(14):1427-1432.

4. McDevitt JJ, Lees PS, McDiarmid MA. Exposure of hospital pharmacists and nurses to antineoplastic agents. J Occup Med 1993; 35(1):57-60.

5. Schmaus G, Schierl R, Funck S. Monitoring surface contamination by antineoplastic drugs using gas chromatography-mass spectrometry and voltammetry. Am J Health Syst Pharm 2002;59(10):956-961.

6. Sessink PJ, Boer KA, Scheefhals AP, Anzion RBM, Bos RP. Occupational exposure to antineoplastic agents at several departments in a hospital. Environmental contamination and excretion of cyclophosphamide and ifosfamide in urine of exposed workers. Int Arch Occup Environ Health 1992;64(2):105-112.

7. Sessink PJ, Anzion RB, Van den Broek PHH, Bos RP. Detection of contamination with antineoplastic agents in a hospital pharmacy department. Pharm World Sci 2003;14(1):16-22.

8. Acampora A, Castiglia L, Miraglia N, Pieri M, Soave C, Liotti F, et al. A case study: contamination of cyclophosphamide due to working practices and cleaning procedures in two Italian hospitals. Ann Occup Hyg 2005;49(7):611-618.

9. Fransman W, Vermeulen R, Kromhout H. Dermal exposure to cyclophosphamide in hospitals during preparation, nursing and cleaning activities. Int Arch Occup Environ Health 2005;78(5):403-412.

10. Kromhout H, Hoek F, Uitterhoeve R, Huijbers R, Overmars RF, Anzion $\mathrm{R}$, et al. Postulating a dermal pathway for exposure to anti-neoplastic drugs among hospital workers. Applying a conceptual model to the results of three workplace surveys. Ann Occup Hyg 2000;44(7):551-560.
11. Sessink PJ, Van de Kerkhof MC, Anzion RB, Noordhoek J, Bos RP. Environmental contamination and assessment of exposure to antineoplastic agents by determination of cyclophosphamide in urine of exposed pharmacy technicians: Is skin absorption an important exposure route? Arch Environ Health 1994;49(3):165-169.

12. Turci R, Sottani C, Spagnoli G, Minoia C. Biological and environmental monitoring of hospital personnel exposed to antineoplastic agents: a review of analytical methods. J Chromatogr B Analyt Technol Biomed Life Sci 2003;789(2):169-209.

13. Fransman W, Vermeulen R, Kromhout H. Occupational dermal exposure to cyclophosphamide in Dutch hospitals: a pilot study. Ann Occup Hyg 2004;48(3):237-244.

14. Sabatini L, Barbieri A, Tosi M, Violante FS. A new high-performance liquid chromatographic/electrospray ionization tandem mass spectrometric method for the simultaneous determination of cyclophosphamide, methotrexate and 5-fluorouracil as markers of surface contamination for occupational exposure monitoring. J Mass Spectrom 2005;40(5):669-674.

15. Chu WC, Barnjak T. British Columbia healthcare workers exposure to carcinogenic substances [lecture]. British Columbia Healthcare Workplace Health, Safety \& Wellness Conference; 2007 Sep 17-18; Kelowna (BC).

16. Sanagi MM, Ling SL, Nasir Z, Hermawan D, Ibrahim WAW, Abu Naim A. Comparison of signal-to-noise, blank determination, and linear regression methods for the estimation of detection and quantification limits for volatile organic compounds by gas chromatography. J AOAC Int 2009;92(6):1833-1838.

17. Hornung RW, Reed LD. Estimation of average concentration in the presence of non-detectable values. Appl Occup Environ Health 1990; 5(1):46-51.

18. Summaries and evaluations: cyclophosphamide (group 1). Lyon (France): International Agency for Research on Cancer; 1987 [updated 1998 Feb 9; cited 2010 Feb 8]. Available from: www.inchem.org/documents/iarc/ suppl7/cyclophosphamide.html

19. Harrison BR. Risks of handling cytotoxic drugs. In: Perry MC, editor. The chemotherapy source book. 3rd ed. Philadelphia (PA): Lippincott, Williams and Wilkins; 1999. p. 566-582.

20. Falck K, Gröhn P, Sorsa M, Vainio H, Heinonen E, Holsti LR. Mutagenicity in urine of nurses handling cytostatic drugs. Lancet 1979; 1(8128):1250-1251.

21. Cavallo D, Ursini A, Perniconi B, Di Francesco A, Giglio M, Rubino FM, et al. Evaluation of genotoxic effects induced by exposure to antineoplastic drugs in lymphocytes and exfoliated buccal cells of oncology nurses and pharmacy employees. Mutat Res 2005;587(1-2):45-51.

22. Yoshida J, Kosaka H, Tomioka K, Kumagai S. Genotoxic risks to nurses from contamination of the work environment with antineoplastic drugs in Japan. J Occup Health 2006;48(6):517-522.

23. Fransman W, Roeleveld N, Peelen S, de Kort W, Kromhout H, Heederik D. Nurses with dermal exposure to antineoplastic drugs: reproductive outcomes. Epidemiology 2007;18(1):112-119.

24. McDiarmid MA, Oliver MS, Roth TS, Rogers B, Escalante C. Chromosome 5 and 7 abnormalities in oncology personnel handling anticancer drugs. J Occup Environ Med 2010;52(10):1028-1034.

25. Colligan SA, Horstman SW. Permeation of cancer chemotherapeutic drugs through glove materials under static and flexed conditions. Appl Occup Environ Hyg 1990;5(12):848-852.

26. Connor TH, Sessink PJ, Harrison BR, Pretty JR, Peters BG, Alfaro RM, et al. Surface contamination of chemotherapy drug vials and evaluation of new vial-cleaning techniques: results of three studies. Am J Health Syst Pharm 2005;62(5):475-484.

27. Zeedijk M, Greijdanus B, Steenstra FB, Uges DRA. Monitoring exposure of cytotoxics on the hospital ward: measuring surface contamination of four different cytotoxic drugs from one wipe sample. Eur J Hosp Pharm 2005;11(1):18-22.

Chun-Yip Hon, MSC(A), CIH, CRSP, is a PhD candidate in the Schoo of Population and Public Health, The University of British Columbia, Vancouver, British Columbia. At the time this study was performed, 
he was also with Disability Management and Safety, Vancouver Coastal Health, Vancouver, British Columbia.

George Astrakianakis, PhD, is with the School of Population and Public Health, The University of British Columbia, Vancouver, British Columbia. At the time this study was performed, he was also with Disease Prevention in the Occupational Health and Safety Agency for Healthcare in British Columbia.

Quinn Danyluk, MSc, CIH, is with the Workplace Health Department, Fraser Health, Burnaby, British Columbia.

Winnie Chu, PhD, is with the School of Population and Public Health, The University of British Columbia, Vancouver, British Columbia.
Address correspondence to:

Chun-Yip Hon

School of Population and Public Health

The University of British Columbia

Third Floor, 2206 East Mall

Vancouver BC V6T 1 Z3

e-mail: cyhon1@interchange.ubc.ca

\section{Acknowledgements}

This study was funded by the British Columbia Environmental and Occupational Health Research Network. The authors would like to thank Tom Barnjak and Summer Reveley for their assistance with data collection and analysis. They would also like to acknowledge Dr. Kay Teschke, School of Population and Public Health, The University of British Columbia, for reviewing the manuscript before submission.

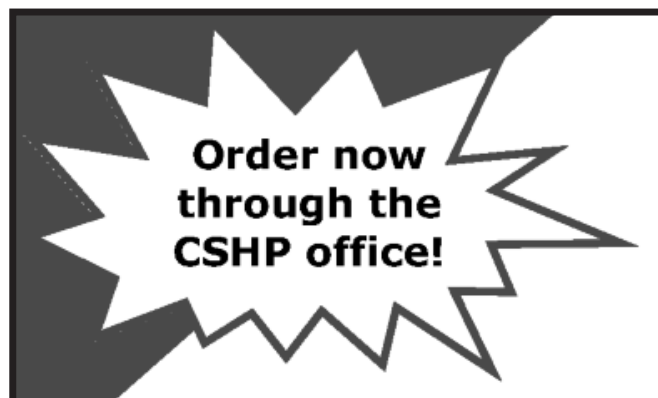

\section{Safe and Effective}

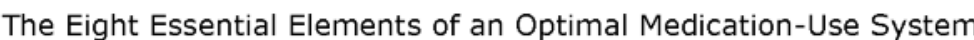

Editor: Neil J. MacKinnon, PhD, FCSHP

Medication is the most relied-upon treatment in health care today. Despite its importance, the current medication-use system suffers from problems related to lack of safety and quality. Safe and Effective explores the medication-use system and, more importantly, provides concrete and straightforward strategies for improving it.

"The patient safety movement is profoundly changing the face of modern health care. This effort by Neil MacKinnon and his capable and progressive group of colleagues is a "must read" for clinicians, practitioners, academics and students who are part of this important journey. This addition to the literature will assist in advancing patient safety practices for Canadian caregivers and will most certainly benefit those we all serve."

- Phil Hassen, CEO, Canadian Patient Safety Institute

Now available to order through the CSHP office - $\$ 81$ for CSHP members and $\$ 90$ for nonmembers (plus applicable taxes and shipping). Please find our order form online at www.cshp.ca under the "Products and Publications" drop-down menu. 